Tropical Journal of Pharmaceutical Research April 2013; 12 (2): 239-245

ISSN: $1596-5996$ (print); 1596-9827 (electronic)

(c) Pharmacotherapy Group, Faculty of Pharmacy, University of Benin, Benin City, 300001 Nigeria.

All rights reserved.

Available online at http://www.tjpr.org

Original Research Article

http://dx.doi.org/10.4314/tjpr.v12i2.17

\title{
Determination of Venlafaxine and Modafinil in Individual Tablet Dosage Forms using Single RP-HPLC Method
}

\section{Mohammad Younus ${ }^{1 *}$, Md Fasiuddin Arif ${ }^{2}$, M Paul Richards ${ }^{3}$ and D Bharat Kumar $^{4}$}

${ }^{1}$ Chandra Labs, ${ }^{2}$ Dr. Reddy's Laboratories Ltd, ${ }^{3}$ Malla Reddy College of Pharmacy, Hyderabad Andhra Rkadesh India, ${ }^{4}$ Vignan Institute of Pharmaceutical Sciences, Nalgonda Dist, Andhra Pradesh, India

*For correspondence: E-mail: mdyounus1127@gmail.com; Tel: +91-8686062421

Received: 19 June 2012

Abstract

Purpose: To develop a simple and selective isocratic method for eabter cion of veplaff Line and modafinil in tablet dosage forms.

Methods: The compounds were analyzed on Waters symm y 1 column $\mathrm{mm} 250 \mathrm{~mm}$ i.d, $5 \mu \mathrm{m}$ ) using a mobile phase consisting of a mixture of ammonh $n$ acd buffer ( $p \AA$ adjusted to 4.0 with glacial acetic acid):10\% methanol in acetonitrile, in the of 60 . The flow was $1.0 \mathrm{ml} / \mathrm{min}$ and column effluents were monitored at $225 \mathrm{~nm}$. Ne n thod was alidated laccording to $1 \mathrm{CH}$ guidelines.

Results: Venlafaxine and modafinil were eluted wi respectively. The method was linear in the range of 1 The relative standard deviation (\%RSD) concentration standard deviation (\%RSD) was < 1 for bo prugs while njean recovery values at different variations in the method were made.

Conclusion: The proposed method is accurd routine analysis of the individual drugs in formul

Keywords: Venlafaxine, Modafinil, Isacratic meth

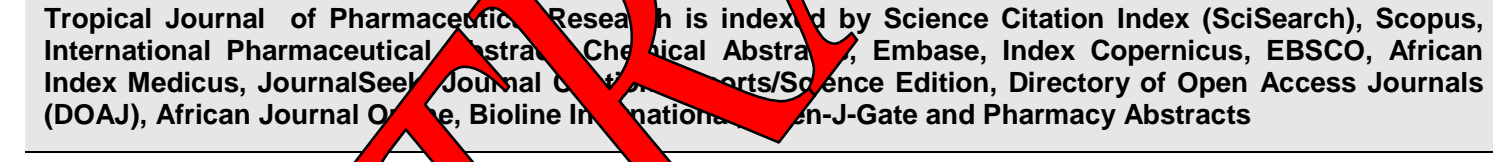

\section{INTRODUCTIOY}

Venlafaxine is third-generation, tructurally novel phenethy icyclio antidepres int [1]. Venlafaxine inhibits un fosomal relaptake of both serotopind and nonalin, is is also a relatively san hibitor dopar ne re-uptake [2].

Modafinil

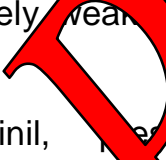

\section{narcolepsy,}
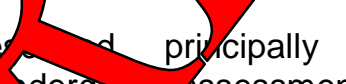

to treat ather conditions. The $\lambda$ uschemical substrates of modafinil are unreso ed. It has been postulated that modafinil enhances wakefulness by modulating dopamine, norepinephrine, or serotonin transporter activities [3].

There are several methods reported for the determination of venlafaxine in biological fluids [4-7] However, for its determination in drug formulations only two methods have been reported [8-9].

For determination of modafinil in biological fluids [10-14] and formulations [15-16], some methods have been reported. The aim of this present study is to develop a single method for the 
determination of venlafaxine and modafinil in their respective dosage forms.

\section{EXPERIMENTAL}

\section{Materials and equipment}

Waters High Performance Liquid Chromatographic HPLC system equipped with a diode array detector and auto-sampler was used. Waters symmetry C18 column (4.6 mm x 250 $\mathrm{mm}$ i.d) was used for separation. Chromatographic and integrated data were recorded using Empower 2 software. All the reagents were of analytical grade unless stated otherwise. Milli Q water, HPLC-grade acetonitrile (Rankem, Mumbai, India), methanol (Rankem, Mumbai, India) and ammonium acetate (AR grade, S.D. Fine Chem, Mumbai, India) were used. All solutions were filtered through $0.45 \mu \mathrm{m}$ membrane filters procured from Pall Pharma Lab Filtration Pvt Ltd (Mumbai, India).

\section{Preparation of standard solutions}

Twenty tablets of venlafaxine were accur weighed, ground to powder and pow ver equivalent of $25 \mathrm{mg}$ ( 1 tablet) of active ingredie was taken into a $50 \mathrm{ml}$ volumetri tra dissolve in $35 \mathrm{ml}$ of $50 \%$ methanol in y $\mathrm{er}$ (di) pt), ultra sonicated for about 10 min filt $d$ an volume made up to the mark with $\bmod$ did t. solution, $0.5 \mathrm{ml}$ of solut was tran rrea w $\mathrm{ml}$ volumetric flask, 5 i diluent $\mathrm{m}$ added, sonicated to mix and volu was mad up to mark with diluent.

Ten milligrams f modafinil working tandard was taken into a Ta volu etric flask, ssolved in 4-5 $\mathrm{ml}$ of diluent $\mathrm{A}$-sonicgted for about 10 min, filter and the lume ma ve up to the mark with $y$ at it (Std lard $\$$ ck). From this solut $0.2 \mathrm{n}$ of soluth w transferred to 10 $\mathrm{ml}$ volu tric ask, $5 \mathrm{ml}$ diluent was added, sonicated the yolume was made up to mark with d

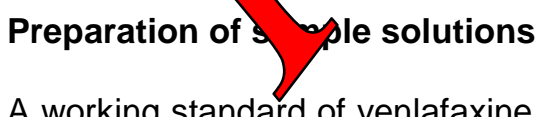

A working standard of venlafaxine $(12.5 \mathrm{mg})$ was taken into a $25 \mathrm{ml}$ volumetric flask, dissolved in $15 \mathrm{ml}$ of diluent, ultra-sonicated for about $10 \mathrm{~min}$, filtered and the volume made up to the mark with the diluent (Standard Stock). From this solution, $0.5 \mathrm{ml}$ of solution was transferred to $10 \mathrm{ml}$ volumetric flask, $5 \mathrm{ml}$ of diluent was added, sonicated to mix and the volume made up to mark with diluent.
Twenty tablets of modafinil were accurately weighed, grounded to powder and powder equivalent of $200 \mathrm{mg}$ (1 tablet) of active ingredient was taken into a $100 \mathrm{ml}$ volumetric flask, dissolved in $70 \mathrm{ml}$ of diluent, ultrasonicated for about 10 min filtered and the volume made up to th mian the diluent. From this solution, $1 \mathrm{ml}$ d olution was transferred to a $10 \mathrm{~m}$ plumetric sk, $5 \mathrm{ml}$ of diluent was adde sol gted to $y$ and the volume made up 10 nark w diluent.

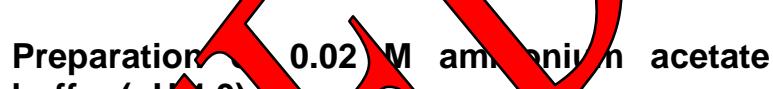
buffer $(p \forall>0)$

Ammd acetate 07972 was transferred to 2 L Jumetric $h$ k. y ater $(700 \mathrm{ml})$ was ad Yed and pnicated to ssolve and degas, throug $2.45 \mu \mathrm{m}$ ther paper and volume was made up to $e$ mark with water. The $\mathrm{pH}$ of the resultant soluk was adjusted to 4.0 with placial acetic acid and sonicated for $2 \mathrm{~min}$ for oper mixing

Pration $10 \%$ methanol in acetonitrile

lethanol $(45 \mathrm{ml})$ was taken in a $500 \mathrm{ml}$ a curing cylinder, made up to volume with acet trile and sonicated for $2 \mathrm{~min}$ for proper miximg.

\section{bystem suitability}

Standard solutions of venlafaxine and modafinil were injected six times and chromatograms were recorded. Relative standard deviation (\% RSD) of retention times (Rt) and peak areas were calculated. The mean of tailing factor (T. Factor) and theoretical plates (T. Plates) were also calculated.

\section{Specificity}

Blank solution (mobile phase), standard solutions, sample solutions and placebo solution (sample solution but excluding active ingredients) were injected separately into the system and chromatograms were recorded.

\section{Precision}

Six different samples of both drugs were analyzed and \% RSD of assay values was calculated.

\section{Ruggedness (Intermediate precision)}

The analysis was performed by a second analyst on Schimadzu HPLC system. The assay of six 
different samples was performed and \% RSD of assay values was calculated.

\section{Linearity}

Solutions in the concentration range of $1-50$ $\mu \mathrm{g} / \mathrm{ml}$ were injected and chromatograms were recorded.

\section{Accuracy}

Accuracy of method was measured in terms of \% recovery. Sample solutions were prepared at three different concentration levels, i.e., 80, 100 and $120 \%$. A predetermined amount of standard was added to these solutions and \% recovery was determined by assaying the solutions.

\section{Robustness}

Slight variations in buffer $\mathrm{pH}$, mobile phase composition, column temperature and flow rate were carried out and standard solution was injected. Six replicates and system suitability tests were performed and the validation parameters indicated above were evaluated.

\section{Solution stability}

For mobile phase stability, mobil se was prepared and stored in a ro gerat The analysis was performed using iro ply pared sample and standard solutio pon fi \& and second day. For sample soy tion stabil sain and standard solution / pre prepd at specification level and fored o a refrigh tor The analysis was penformed using fre $y$ prepared mobile pl se on the fin and second day.

\section{RESULTS}

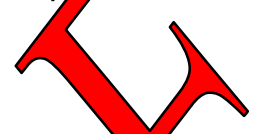

Kromasil CTo column and Dobile phase contain 0.02 ammon of etate ( $\mathrm{pH} 4.0)$, $10 \%$ meth ol in acetonitrile $0: 40$ ) were found to be suitad alvsis b both venlafaxine and modafin The er chromatographic conditions optims $\$$ were flow rate of $1.0 \mathrm{ml} / \mathrm{min}$, detection waveld by of $225 \mathrm{~nm}$, column temperature of $40^{\circ} \mathrm{d}$, injection volume of $20 \mathrm{ml}$, diluent methanol:water $(50: 50, \mathrm{v} / \mathrm{v})$, and a run time of $10 \mathrm{~min}$.

\section{System suitability}

To check the system and column performance, the standard solution was injected six times and the following parameters were monitored. System suitability results are shown in Table 1. Tailing factor was < 1.5 for both venlafaxine and modafinil. Theoretical plates were 4500 for venlafaxine and 5500 for modafinil. \%RSD of retention time and peak area was $<1 \%$ for both venlafaxine and modafinil.

Table 1: System suitability results

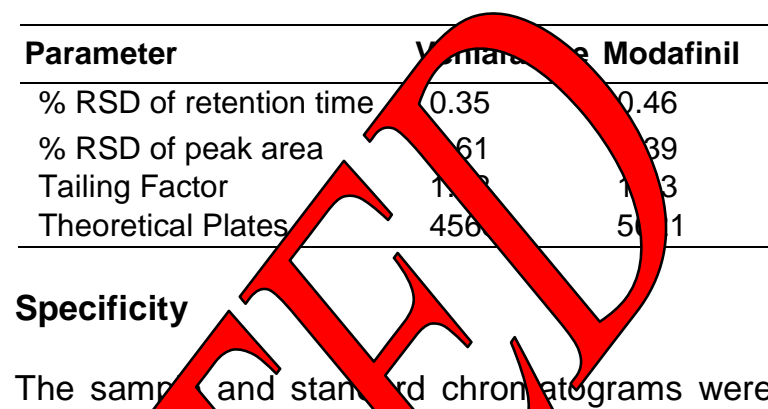
identical o were nd paks in both blank and placebo chrol tograms $h \mathrm{cb}$ shows that there was interferd e of excip hts in the analysis of the angs. Typ y chromatograms are shown i) Fig 1.

\section{P cision and iptermediate precision}

The RSD valu/s of venlafaxine and modafinil for ad ecision were 0.71 and 0.58 spective, at for intermediate precision these a) 83 and 0.84 for venlafaxine and modafinil spe $y$.

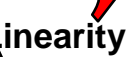

Y

axine and modafinil showed linearity in the ange $1-50 \mu \mathrm{g} / \mathrm{mL}$, and was represented by the following linear regression equations: $Y=$ $34918 X+1013\left(r^{2}=0.9998\right), Y=26759 X+3286$ $\left(r^{2}=0.9998\right)$, respectively.

\section{Accuracy}

Recoveries of venlafaxine and modafinil were between 98.0 and $102.0 \%$, indicating good accuracy of the developed method. The results are shown in Table 3.

\section{Robustness}

In all cases where deliberate changes were made to the procedure, no significant changes were observed in the results. \%RSD of peak area and retention time were $<1 \%$. The results are shown in Table 4.

\section{Solutions stability}

The drug solution and mobile phase were stable up to 48 hours in refrigerated condition. There was not much change in assay value; the results are shown in table no 5. 

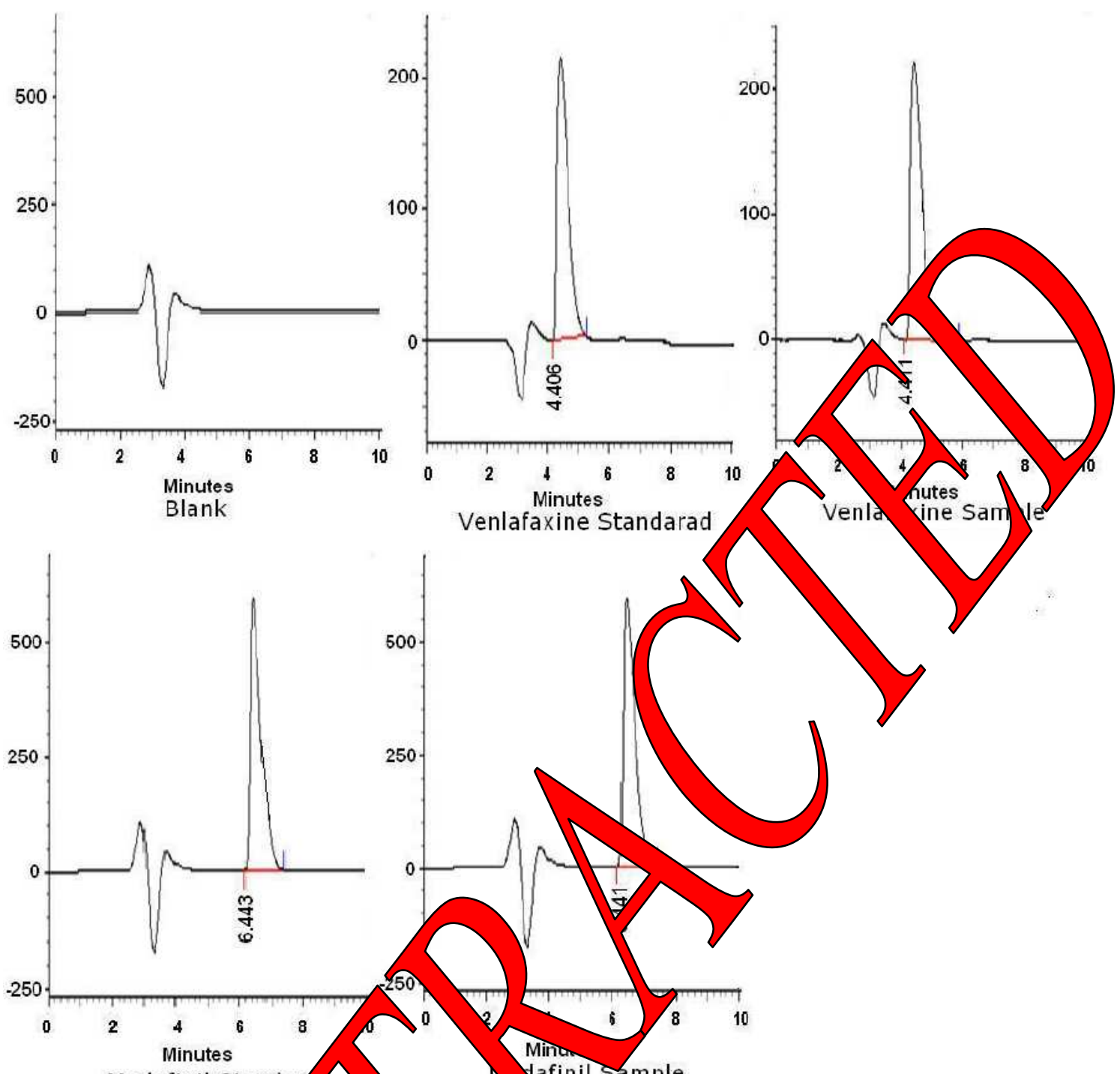

Venlafaxine Standarad

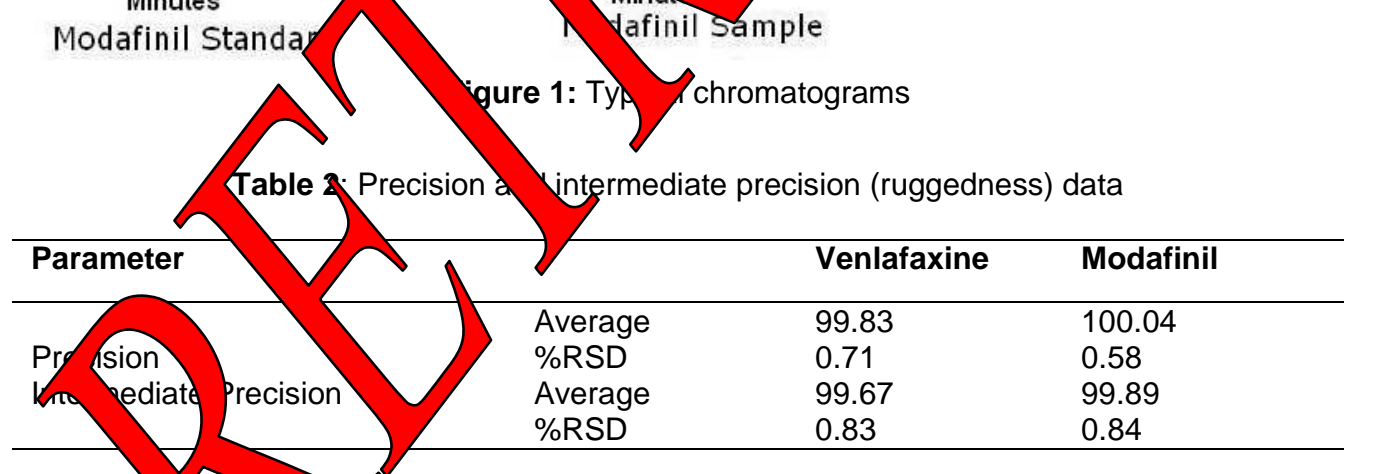

Table 3: Accuracy (\% Recovery) results

\begin{tabular}{|c|c|c|c|c|c|c|}
\hline \multirow[b]{2}{*}{$\%$ Conc. } & \multicolumn{3}{|c|}{ Venlafaxine } & \multicolumn{3}{|c|}{ Modafinil } \\
\hline & $\begin{array}{l}\text { Almount } \\
\text { added } \\
(\mu \mathrm{g} / \mathrm{ml})\end{array}$ & $\begin{array}{c}\text { Amount } \\
\text { found } \\
\text { ( } \mu \mathrm{g} / \mathrm{ml})\end{array}$ & $\begin{array}{c}\% \\
\text { Recovery }\end{array}$ & $\begin{array}{c}\text { Amount } \\
\text { added } \\
\text { ( } \mu \mathrm{g} / \mathrm{ml})\end{array}$ & $\begin{array}{c}\text { Amount } \\
\text { found } \\
(\mu \mathrm{g} / \mathrm{ml})\end{array}$ & $\begin{array}{c}\% \\
\text { Recovery }\end{array}$ \\
\hline 80 & 5.00 & 4.98 & 99.60 & 5.00 & 4.97 & 99.40 \\
\hline 100 & 10.00 & 9.92 & 99.20 & 10.00 & 9.95 & 99.50 \\
\hline 120 & 15.00 & 14.93 & 99.53 & 15.00 & 14.96 & 99.73 \\
\hline
\end{tabular}


Table 4: Results of robustness

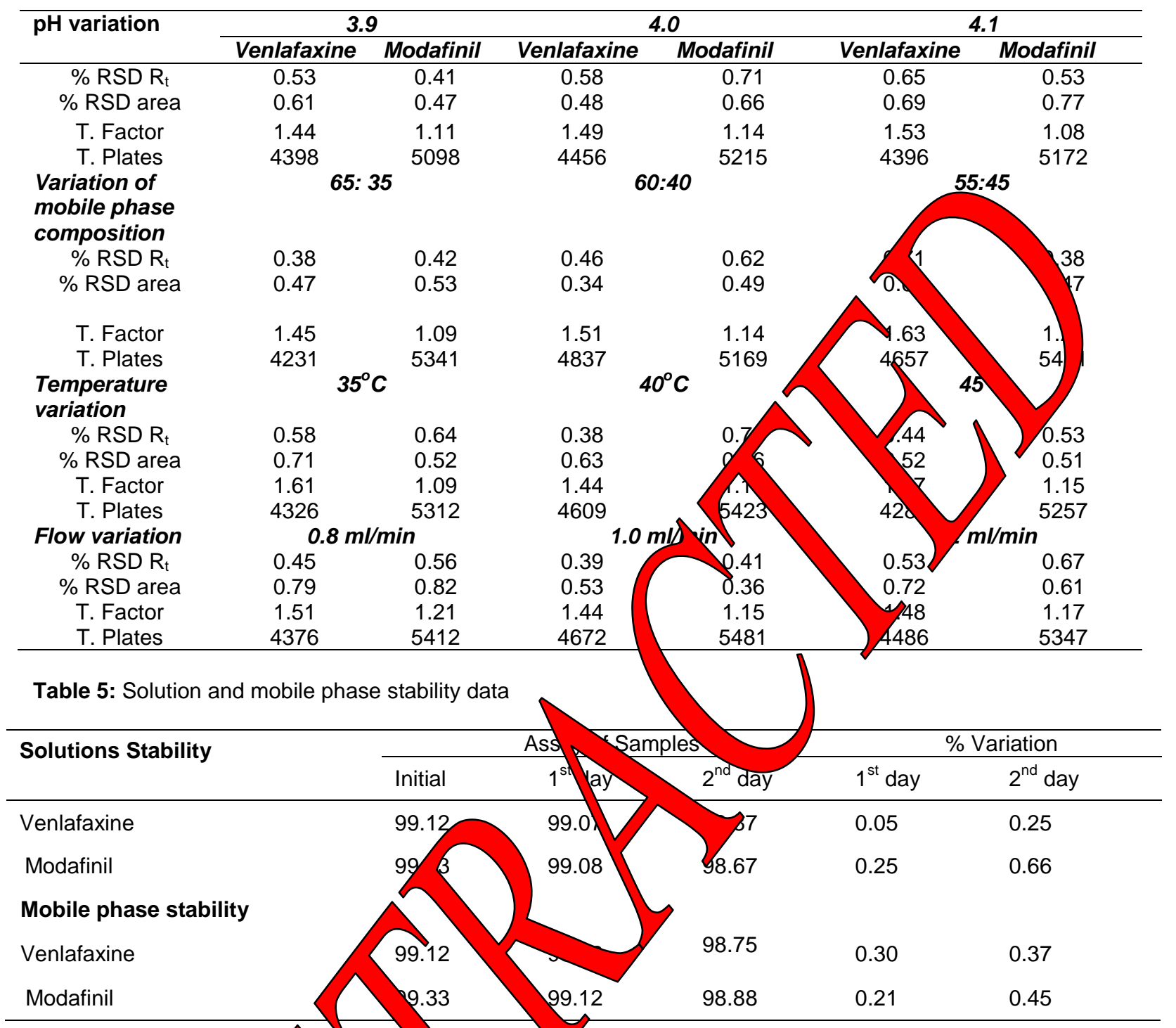

\section{DISCUSSION}

Venlafaxine and find finil astructural Close and have similar pol tid Doth drugs were analysed by $r$ se pha HPLC of commercial C18 colum o, un p 0.05 ammo am acetate and 0 of assium di /drogenorthophosphate o fers with organ modifiers, viz, methanol and ing Asil C18 did not show any selecth for tin ompounds. Analysis was tried on a Krok sil C18 (4.6 mm x $250 \mathrm{~mm}$ i.d, $5 \mu \mathrm{m}$ particle $\$$ column, using $0.05 \mathrm{M}$ ammonium acetate bu fer and methanol as well as methanol/acetonitrile in varying proportions. In methanol alone, modafinil was not eluted, but when acetonitrile was added, modafinil was eluted (as acetonitrile content increased) and the retention times were high. The compounds were analyzed on Waters C18, (4.6 mm x $250 \mathrm{~mm}$ i. d, $5 \mu \mathrm{m})$, using buffers, methanol and acetonitrile in different proportions. The mobile phase containing $0.05 \mathrm{M}$ ammonium acetate buffer and $10 \%$ methanol in acetonitrile eluted both compounds in less time, with good peak symmetric properties. The concentration of the organic modifier, buffer $\mathrm{pH}$ and column temperature were optimized to separate the two compounds with good resolution in less time.

For efficient analysis of the compounds, various concentrations of acetonitrile were studied. At lower concentrations, it took a longer time for elution of the compounds. Also, there was a slight increase in tailing factor as concentration increased.

Studies were carried out on the effect of buffer $\mathrm{pH}$ on tailing factor and retention times. There was a slight increase in tailing of compounds, while the retention time for venlafaxine increased and resolution decreased as buffer $\mathrm{pH}$ increased 
from 3.0 to 5.0. At $\mathrm{pH} 4.0$, symmetrical peaks with good resolutions were obtained.

The column was maintained at different temperatures ranging from 25 to $50{ }^{\circ} \mathrm{C}$. Tailing was reduced with increasing temperature for venlafaxine and a slight increase was observed for modafinil. Retention times decreased slightly with increasing temperature, but the peaks became sharp, and resolution was good for the compounds at $40^{\circ} \mathrm{C}$.

Good symmetrical peaks were obtained with the mobile phase, $0.05 \mathrm{M}$ ammonium acetate $(\mathrm{pH}$ 4.0): $10 \%$ methanol in acetonitrile $(60: 40 \mathrm{v} / \mathrm{v})$ on Waters C18 (4.6 mm x $250 \mathrm{~mm})$ column maintained at $40{ }^{\circ} \mathrm{C}$. Flow rate was kept at $1.0 \mathrm{ml} / \mathrm{min}$. The UV overlaid spectra of both venlafaxine hydrochloride and modafinil showed that both drugs absorb appreciably at $225 \mathrm{~nm}$; hence, $225 \mathrm{~nm}$ was selected as the detection wavelength. The retention time of venlafaxine hydrochloride was $4.4 \mathrm{~min}$ and that of modafinil $6.3 \mathrm{~min}$. Asymmetric factor for venlafaxine hydrochloride was $<1.5$ and for modafinil, it was $<1.2$.

Relative standard deviation (\% RSD) of retention times (Rt) and peak areas were $<1$ and means of tailing factor $(>2)$, resolution factor $(>2)$ and theoretical plates (> 2000) were well within the limits, hence the method passed suitability tests. There was no interf ence excipients with the analysis of the an Th standard and sample chromat ams we identical, which proves that specific. The mean amount of and $100.04 \%$ for modafin and enlafaxind respectively. When analysin wals perh ned by a second analyst on a sec/ a system, Ry was < $1 \%$, which proves th precisjen of the $\lambda$ thod. The method showela hod Ii) earity for venlafaxine and modafinh the rethog is robust and unaffected hy smak ariations in test conditions. The $\pi$ als atisfied stability requirements CONCLUSIO

A simple and accurd reverse phase HPLC method has been byeloped for the determination of venlafax e and modafinil. The method was validated as per $\mathrm{ICH}$ guideline in terms of specificity, precision, accuracy, linearity, limit of detection, ruggedness, robustness and solutions and mobile phase stability. A single method can thus be used for the routine analysis of venlafaxine and modafinil in dosage forms.

\section{REFERENCES}

1. Goodman \& Gilman's, The Pharmacological Basis of Therapeutics, 11th edn, McGraw Hill Medical Publishing Div, London, 2005; pp 447-485.

2. Holliday MS, Benfield P. Venlafaxine. A Review of its Pharmacology and Therapeutic Potential in Depression. Drugs. 1995; 49(2): 280-294.

3. Madras BK, Xie Z, Lin Z, Jassen A, Panas H, Lynch L, Johnson R, Livni E, Spencer TJ, Bonab AA, Miller GM, J. Fischman A. Modafinil O-ies Dopamine and Norepinephrine Transp ers Yivo and Modulates the Transporte and Tra Amine Activity in Vitro. I Phar ol Exp The P006; 319(2): 561-569.

4. Raut BB, Kolte BL, Deo A Bagod A, Shinde $A$ rapid and sensity Angh of rmance $n$ id chromatographic hethod for do mination of venlafaxine and esmethy venlafad in hy lan plasma with on tection Liq op fogr Technol. 20 2618 697 (31)

5. Asafu-Adjaye 7 , Faustino Tawakkul A, Lhderson LW, Yu Kwon H. Vah jen and ar Vication of a stabili. And ting HPLC $\backslash$ thod ff/the invitro veten nation gastric and pes pal stability of

6. Pu el NC, Dalalau D, $\bigwedge$ Arama CC. Determination of Venlafaxine Toxic vels From Human Serum by Non-Aqueous \& Ilary Electrophoresis. Farmacia 2010; 58(1): 6) 69.

7. Ch goui $S$, Rudat $S$, Veuthey J. Non-aqueous illary electrontporesis- mass spectrometry for sd tion of enlafaxine and its phase 1 metd eld rophoresis 2001; 22(3): 491-496. R. Stability indicating LC method for
estimation of venlafaxine in pharmaceutical
Lations. J Pharm Biomed Anal. 2002; 28(6): Uations. J Pharm Biomed Anal. 2002; 28(6):

9. (aur J, Si) Iivasan $K K$, Joseph A, Gupta A, Singh $Y$, Srinivas SK, Jain G. Development and validation of stability indicating method for the quantitative Ptermination of venlafaxine hydrochloride in extended release formulation using high performance liquid chromatography. J. Pham. Bioall Sci. 2010; 2(1): 22-26.

Burnat $P$, Robles $F$, Do B. High-performance liquid chromatographic determination of modafinil and its two metabolites in human plasma using solidphase extraction. J Chromatogr B Biomed Sci Appl. 1998; 706(2): 295-304.

11. Moachon G, Matinier D. Simultaneous determination of modafinil and its acid metabolite by highperformance liquid chromatography in human plasma. J Chromatogr B Biomed Appl. 1994; 654(1): 91-96.

12. Schwertner HA, Kong SB. Determination of modafinil in plasma and urine by reversed phase high performance liquid-chromatography. J Pharm Biomed Anal. 2005; 37(3): 475-479.

13. Gorman SH. Determination of modafinil, modafinil acid and modafinilsulfone in human plasma utilizing liquid-liquid extraction and high-performance liquid chromatography. J Chromatogram B Anal Tech Biomed Life Sci. 2002; 767(2): 269-276.

14. Schwertner HA, Kong SB. Determination of modafinil in plasma and urine by reversed phase highperformance liquid-chromatography. J Pharm Biomed Anal. 2005; 37(3): 475-479.

15. Swetha $K$, Mohideen S, Satyanarayana $T$, Narasimha $\mathrm{RCH}$, Suresh KP, Shyamala M. Determination and Validation of Modafinil in Pharmaceutical Formulation by RP-HPLC Int Res Pharm and Biomel Sci., 2011; 2(4): 1837-1840. 
16. Bhimanadhuni CNR, Garikapati DR, Karamsetty $S$. Development and Validation of RP-HPLC method for determination of Modafinil in bulk and dosage form. Int C PharmJ. 2012; 1(4): 77-80.

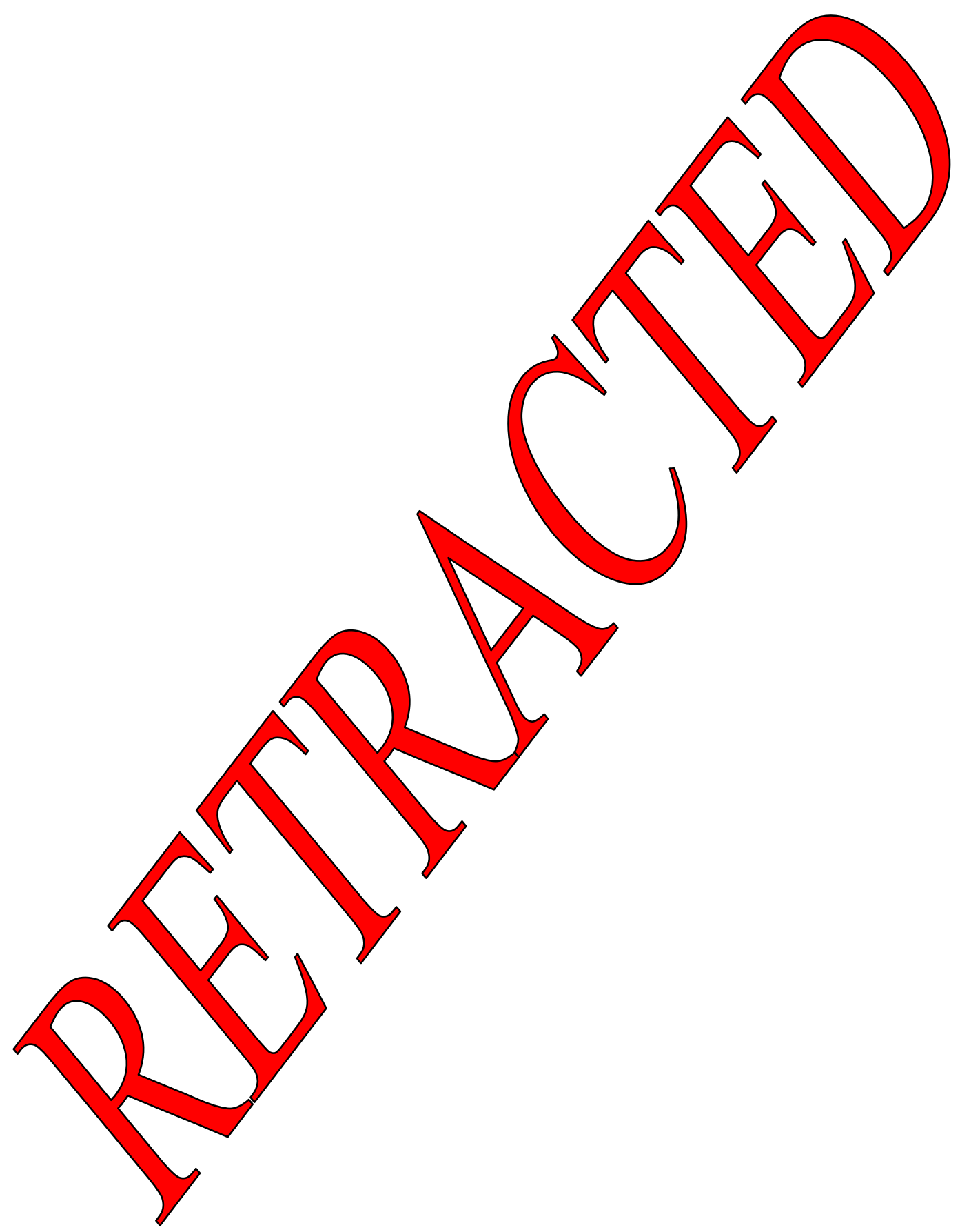

